\title{
Reliable Intelligent Distribution Network Structure
}

\author{
Ninghui Guo and Lijun Qin
}

\begin{abstract}
To establish a reliable, economical and practical, self-healing smart distribution grid is a trend of power system automation technology. This paper combines the current distribution grid automation technology development level and actual project experience by $1000 \mathrm{M}$ industrial Ethernet switches on the integration design, it is easy to constitute a selfhealing optical fiber ring network and makes up a reliable smart distribution grid system, detailed analysis its function and reliability related of the structure. The intelligent power distribution network automation system applied in anqiu power supply company, achieveing good social and economic benefits.
\end{abstract}

Index Terms-Smart distribution network structure, fault isolation, IEEE1588, FTU.

\section{INTRODUCTION}

With the development of the intelligent power grid, the domestic power supply departments should evaluate the current application of distribution network automation system from technology, economy, etc., they are looking forward to more superior distribution network automation mode and more advanced distribution network automation system in the power system can be extended, so as to improve the distribution system of power supply reliability and power quality. With digital technology applied in the substation and the distribution network system, it is providing favorable conditions for distribution network automation development, it appears intelligent products such as intelligent terminal, substation and distribution integrated digital system, intelligent distribution network automation master station system [1], [2].

Intelligent distribution grid need to use modern power electronic technology, communication technology, computer and network technology, advanced sensor and measurement and control technology ,And combining power equipment, monitoring, protection, control, calculation of the distribution grid in normal or emergency condition and power supply department management organically fuses in together, support a large number of access distributed power DG (Distributed Generation),.For the user, providing a more secure, reliable, high quality, and high efficient power.

Smart distribution grid should have the following characteristics [3].

1) Have higher safety and reliability, and can reduce the power fault time and power fault users.

2) Good self-healing recovery ability. When the fault or

Manuscript received March 14, 2013; revised June 14, 2013. This work was supported by Modern Electric Power Research, North China Electric Power University, intelligent distribution network structure research.

The authors are with the Academy of Modern Electric Power Research North China Electric Power University Beijing, China (e-mail: guoninghui1987@163.com, qin33888@sina.com). exceptional situation, quickly found out fault section and anomaly, and corresponding corrective operation, make it does not affect the normal power supply or to minimize the influence degree.

3) Save costs. Smart distribution grid have intelligent remote control to isolation fault, can reduce the operation and maintenance personnel, thus greatly save spending.

4) Improve equipment availability. Based on load realtime management to achieve economic operation, reduce line loss and reduce primarily equipment investment.

5) Support DG access. Through "plug and play (PNP)" technology, grid can contain centralized power generation, a variety of different types of DG, energy storage device.

6) User interaction. According to load rush hour, the users choose using power moment based on different price, such as timing set price, segment price.

7) Visual management. Real-time acquisition distribution grid equipment information, in the image timely show substation and feeder line monitoring circumstances, such as harmonic analysis, failure analysis, etc.

8) Simulation operation function. For training personnel, it provides simulation operation, realizes operation and experimental simulation in dangerous places.

9) Highly integrated. Equipment management and maintenance management, power outage management and power management of all kinds of information system Integrated together, and on this basis to realize the business integration [4].

\section{SYSTEM STRUCTURE} 1.

Distribution automation system structure is shown in Fig.

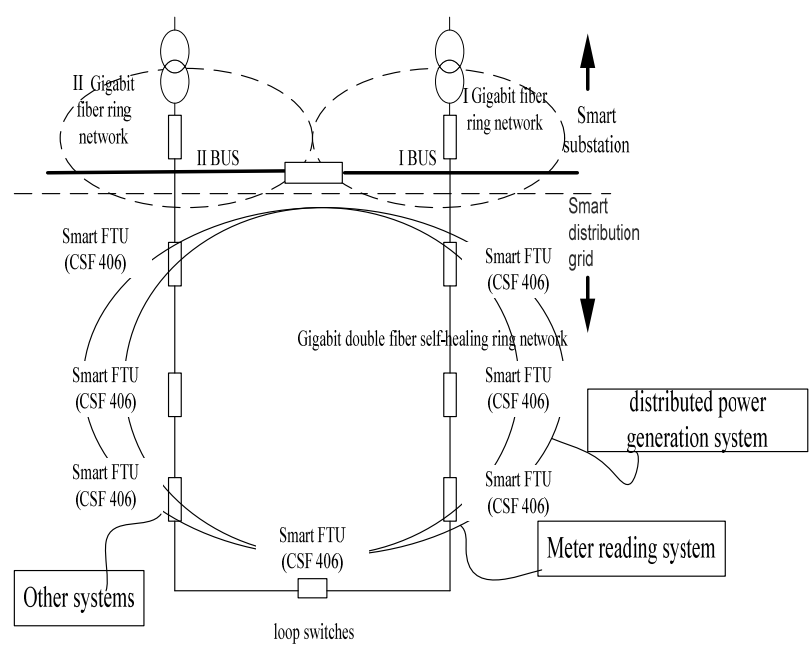

Fig. 1. Distribution automation system structure 
IEEE1588 v2 $<50$ ns time tick

IEC61850-9-21E/ Capping < 50ns error timestamp , sampling value sharing, GOOSE/GSSE $<0.5 \mathrm{~ms}$, High speed communication equipment.

Based on the above conditions of intelligent protection algorithm, can realize millisecond level rapid fault isolation, and millisecond level rapid recovery [5].

Due to the FTU and 1000M industrial Ethernet switches on the integration design, it is easy to constitute a selfhealing optical fiber ring network, optical fiber tangent network. The FTU have enough communication resources, the distributed power generation intelligent system, meter reading system, other intelligent system and TTU and so on all can access to optical fiber communication network conveniently. If intelligent power distribution grid and smart substation communication network connect, substation communication network and dispatching system are linked together, so, dispatching system, substation system, power distribution grid system, a distributed system, will constitute an "information superhighway" in intelligent power grid.

\section{A. The Realization of the Automatic Feeder}

1) Based on intelligent FTU, TTU sharing information, it can achieve accurate positioning fault area once, a resection of fault point once. On the basis of the distribution system to realize the real-time monitoring, load transfer function, the effective utilization of system resources;

2) realize the distribution grid load flow analysis and calculation, distribution grid equipment management and control [6];

3) dispatching center and office automation system are linked to realize data sharing [7];

4) lay foundation for the remote meter reading, public transformer control and business automation

\section{B. Meet IEC61850 Digital FTU Device CSF406}

CSF406 digital FTU hardware structure and CSF6000 (10 $\mathrm{kv}$ substation intelligent device) are similar, but CSF406 generally do not use electronic transformer. But according to the needs of the distribution automation, CSF406 blend in some new fast fault detection, fault isolation, fault location, fault recovery algorithm and the corresponding control strategy, the function of distribution substation of the traditional distribution automation directly down in to digital FTU [8], [9].

\section{New Fault Isolation Scheme Introduction}

1) With the help of CSF406 own hardware and software functions, the GOOSE communication time of digital terminal is between time $<0.5 \mathrm{~ms}$, far higher than requirements of the time spacer layer between equipment GOOSE command transmission time $4 \mathrm{~ms}$ in IEC61850. Using advanced fault detection algorithm, together with quick switch (action time for $20-30 \mathrm{~ms}$ ), can realize to cut off any fault online in distribution grid in $40 \mathrm{~ms}$, selective a reclosing eliminate instantaneity fault. And work together with substation line protection, line protection quick break time delay can be set to 0.15 , as the backup when distribution switch refused to move. Fast fault location is based on digital FTU information sharing in power distribution network;
2) Based on fault judging direction information of FTUs.

3) Fault direction information interaction scope: the FTU fault direction information on the same line and on the same node.

\section{New Recovery Strategy Description}

1) Based on FTU sharing the trip information, using the recovery strategy in FTU to recover load;

2) recovery plan of sub-station (or master station) is based on sharing trip information;

3) If network topology changes or optimizing operation lead to recovery strategy change, Lord, son station will form new recovery strategy, it will be downloaded to the corresponding FTU.

4) In case of fault, based on the sharing information (fault location) and embedded control strategy library, it will select the corresponding recovery plan.

Distribution automation system is based on the intelligent FTU - CSF406, most of the fault isolation and recovery do not need with sub-station, master station to participate in. According to sharing information and the pre-installed control strategy FTU can realize one-time fast fault resection and load recovery quickly.

\section{E. Sub-Station}

Compared with the traditional power distribution automation, in digital distribution automation system, substation function is weakening, main function is the communication with maser station, if there are a few distribution line, can even substation, master station host merger [10], [11].

1) intelligent fault recovery locally:

2) every feeder regional power node switch:

3) know this feeder regional internal power load;

4) Set the biggest power supply of the switch;

5) through the data exchange, it knows the residual power supply maximum ability based on current power supply path;

6) through the data exchange, it knows the power supply of all feeder area 's total load demand;

7) Realize local intelligent recovery, and effectively prevent fault diffusion brought by load transfer.

\section{F. Master Station}

1) Based on the substation layer should electric power dispatching data network is done with the control center communication;

2) Based on IEC61850 standard, the control center complete the far side of the distribution terminal management, maintenance and monitoring;

3) Pieces into GIS system in the control center, based on the GIS system to accomplish fault analysis, power management;

4) Complete rapid power supply recovery locally based on the global optimization, preliminary decision power supply recovery program of the control center [12].

Main software module:

1) SCADA module;

2) GIS module;

3) FDIR module (recovery system);

4) Recovery system database module;

5) Power load flow calculation module. 
6) technology extension as a result of accurate clock

Due to company's each intelligent components have functions of IEC1588 synchronous sampling and time stamp, so host substation application analysis software can at the same time coordinate analysis load flow section, phase Angle difference between different substation feeder (so as to eliminate the influence of the distribution closed loop current), the power load distribution at the same time (to allocate rationally, energy saving effect and emission reduction), etc.

Distribution network system synchronous data acquisition laid a foundation for distribution network fault isolation and restore the dynamic adjustment strategy. which make the foundation for intelligent monitoring and operation optimization (also called fast simulation: FSM) possible.

Distribution network intelligent monitoring tracking distribution network operation state at any time, find the weak link of distribution network operation actively, quickly, capture monitoring points accurately, and provide effective distribution network adjustment strategy, realize distribution network the self-healing, eliminate distribution network operation hidden trouble and avoid subsequent chain of failure, improve power supply reliability, and at the same time, provide users with high quality power.

\section{APPLICATION CASE}

Through the application of IEC61850 standard based on the intelligent terminal FTU and follow IEC61970/61968 standard research center intelligent distribution network automation master station system, Anqiu power supply company and JingZhi substation realized the anqiu distribution network fast fault location, isolation and recovery [13], effectively improve the distribution network automation level.

\section{A. Distribution Network Program}

Research center digital intelligent terminal CSF301 uses the IEC61850 standard and related technology. Based on IEC61850-9-2 part description, digital intelligent terminal realize point to multipoint communication mode, make data information from each digital intelligent terminal can be sharing in the optical fiber ring online, the use of sharing information can realize fault fast positioning, resection, and then realize the rapid distribution network reconstruction.

Distribution network system in any little fault, distribution digital intelligent terminal use share information to obtain adjacent terminal flow state and switch state, judge fault area and fault isolation, and according to the default setting and the current system load condition, fault location, power source information, selection of an optimal reconstruction program to realize quick power restore [14].

According to field test, communication time of two digital intelligent terminals reach to millisecond level, with advanced fault detection algorithm, can realize any fault online positioning and export in a very short time. Fault isolation time should match up switch brake time, selective auto-reclosing eliminate fault instantaneity. And work together with substation line protection, line protection quick break setup a delay as backup to prevent switch rejected the move in Individual limit case

After fault isolation, according to the current situation of the system, distribution network workstation system will ensure the optimal restore power program, before carrying out the reconstruction scheme, Switch the corresponding digital terminal protection setting group to meet the needs of the relationship between the protection after the new operation mode [15].

Through the digital technology, research center further fusion substation and distribution network, digitized substation $10 \mathrm{kv}$ line switch section and digital distribution network system should be combined to form a new variable and digital system; In $10 \mathrm{kv}$ line switch part add digital terminal, and digital switch terminal in distribution line section commonly uses 61850 code to realize point to multipoint communication, according to whether there is a trouble-free current logic, digital terminal itself can be judged whether the switch to trip, achieving an accurate fault area positioning, and realizeing one-time resection of fault point [16]; To overcome drawbacks in the original distribution network automation system using the principle of elimination: multiple reclosing, from the source to the point of contact all switch have to action, to avoid the non fault section switch trip and to switching, improve the power supply reliability of the fault section; from the occurrence of fault, fault processing, Recovery .etc is under control by a digital variable system; Thus selectively to realize fault location and rapid resection fault quickly.

\section{CONCLUSION}

Insight into the level of distribution automation development both at home and abroad is presented in this paper, on the basis of combined with practical engineering experience, reliable structure of smart distribution network has carried on the detailed analysis and elaboration, probing the way it should have the function and its realization, and finally discusses the construction of the key technology of intelligent and reliable distribution network. This article provides reliable intelligent distribution network construction experience, is only the preliminary practice process, and further to perfect its construction.

\section{REFERENCES}

[1] P. F. Pai and W. C. Hong, "Forecasting regional electricity load based on recurrent support vector machines with genetic algorithms," Electric Power Systems Research, vol. 74, no. 3, pp. 417-425. 2005.

[2] S. Fan, C. Mao, J. Zhang, et al., "Forecasting electricity demand by hybrid machine learning model," Lecture Notes in Computer Science, vol. 42, no. 33, pp. 952-963, 2006.

[3] B. Y. Xu, T. Y. Li, and Y. D. Xue, "Smart distribution grid and distribution automation," Automation of Electric Power Systems, vol. 17, no. 7, pp. 38-41, 2009.

[4] K. Xie, Y. Q. Liu, Z. Zhu, et al., "The vision of future smart grid," Electric Power, vol. 41, no. 6, pp. 19-22, 2008.

[5] H. F. Zhang, F. Zhang, and Z. C. Pan, "Automatic fault locating algorithm based on signal injection method for distribution system," Electric Power Automation Equipment, vol. 28, no. 6, pp. 39-43, 2008.

[6] X. Fu, "Decoupling phase domain method for fault analysis of distribution system with distributed generation," Electric Power Automation Equipment, vol. 29, no. 6, pp. 19-23, 2009.

[7] S. Y. Yan, G. Chang, and Y. Wang, "Power distribution network fault locating by on - line detectors," Electric Power Automation Equipment, vol. 28, no. 12, pp. 98-100, 2008.

[8] Y. F. Tang, X. Chen, and H. Z. Cheng, "A phased fault restoration algorithm for distribution system based on coevolutionary algorithm 
of PSO and SA," Power System Technology, vol. 3, no. 16, pp. 71-75, 2008.

[9] N. Wu, Y. Xu, and Y. P. Lu, "New fault location algorithm for distribution network with DG," Automation of Electric Power Systems, vol. 33, no. 14, pp. 77-82, 2009.

[10] Z. G. Lu and Y. X. Dong, "Service restoration strategy for the distribution system with DGs," Automation of Electric Power Systems, vol. 31, no. 1, pp. 89-92, 2007.

[11] Q. W. Gong, F. Iang, and Y. F. Chen, "Virtual reality technique based substation training simulator," Power System Technology, vol. 29, no. 24, pp. 74-77, 2005.

[12] C. B. Li, P. Yang, W. Liu, et al., "An analysis of accumulative effect of temperature in short-term load forecasting," Automation of Electric Power Systems, vol. 33, no. 9, pp. 96-99, 2009.

[13] X. W. Li, Z. Q. Wang, M. Fang, et al., "Daily load forecasting based on hourly area weather data," Power System Protection and Control, vol. 37, no. 3, pp. 36-40,2009.

[14] D. X. Niu, J. Wang, L. Li, et al., "Short-term load forecasting using adaptive ANN based on rough set and decision tree," Electric Power Automation Equipment, vol. 29, no. 10, pp. 30-34,2009.

[15] Z. J. Li and Y. Yuan, "Smart microgrid: a novel organization form of smart distribution grid in the future," Automation of Electric Power Systems, vol. 33, no. 17, pp. 42-46, 2009.

[16] M. Ding, Y. Zhang, and M. Q. Mao, "Key technologies for microgrids being researched," Power System Technology, vol. 33, no. 11, pp. 6-10, 2009.

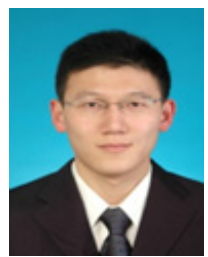

N. H. Guo was born in China's hebei province on September 26, 1987. In June 2011, graduated from China agricultural university in Beijing .In September the same year study for a master's degree in Academy of Modern Electric Power Research,North China Electric Power University in beijing,china. the main research direction for power system automation, distribution network automation.
He began as an intern in September 2012 in Beijing sifang huaneng power control co., LTD., intern, mainly involved in smart grid research and development and construction projects.

Mr. Guo has published papers "Design Scheme of Condition Monitoring System for Smart Substation"at the 2012 The International Workshop on Electrical Engineering and Control (IEEC 2012).

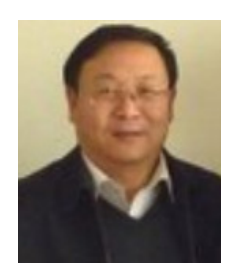

L. J. Qin is a professor who was born in China's hebei province 1962.in July 1982, graduated from xi 'an jiaotong university, electrical engineering department of electric power system and its automation major, attains the bachelor's degree; In August 1982 to September 85 in hebei province electricity power relay protection research, on the operation management and scientific research work, participate in during Yang Jixun professor presided over the domestic first set of microcomputer protection of scientific research and development work;

In September 1985 and was admitted to study for a master's degree, a postgraduate student in school of Beijing north China electric power department, and obtained a master's degree in January 1988 and teaches; In 1996 promoted to professor title; Between January 1988 and May 2007 in north China electric power university institute of electric engineering and the quartet professional on microcomputer protection for electric power system and its automation, power system simulation, substation integrated automation, distribution network automation, etc in the direction of scientific research and teaching work;

Mr. Qin began to work at north China electric power university of modern electric power research institute digital electric power and energy research center In June 2007. Has presided over and participated in over 10 scientific research projects (including four item is ministry of key research projects), especially after 95 , was awarded a prize of provincial scientific research three; In scientific research work, to grasp the scientific research and the development trend, stand in the forefront of this field, its main research projects have made great social and economic benefits. 